\title{
Imprinting or exposure learning in rats given early auditory stimulation
}

\author{
HENRY A. CROSS, WITTENBERG UNIVERSITY \\ CHARLES G. HALCOMB AND WILLIAM W. MATTER, TEXAS TECHNOLOGICAL COLLEGE
}

\begin{abstract}
Albino rats were raised from birth in an environment of music in an attempt to assess the effects of early exposure to specific musical forms on subsequent preference behavior. Ss were housed in groups in sound chambers. One group was exposed to selections of the music of Mozart for $12 \mathrm{hr}$. a day for 52 days; a second group to the music of Schoenberg. In the test situation when the $S$ s were given an opportunity to select Mozart or Schoenberg music, the Mozart Ss displayed a significant preference for Mozart music. No preference was found among the Schoenberg $S$ s or among the control Ss raised in a similar environment devoid of music. These results show that early exposure may influence later choice behavior and perhaps point to some attachment process analogous to imprinting. However, questions arise as to why only the Mozart Ss "imprinted." A possible explanation for this is offered.
\end{abstract}

Sluckin (1965) has celled attention to the possible role that imprinting or "exposure learning" may play in young and developing organisms and has suggested that such forms of learning may be more general than laboratory demonstrations have indicated. Sluckin's view is that sensory input or exposure learning, per se, may subsequently benefit the organism in its attempt to cope with its environment and may, in fact, substantially contribute to the general matrix from which the more specific associative forms of learning emerge. The studies of Gibson (e.g., Gibson \& Walk, 1956; Gibson, Walk, Pick, \& Tighe, 1958) with rats are of interest in this context as is the demonstration of Burtt (1932) that his 10-year-old son was materially benefitted in learning passages of Greek poetry which had been read to him as an infant.

It seems plausible that some form of exposure learning may underlie and profoundly influence the development of preference or attachment behavior. The theory of Dember \& Earl (1957) and the experimental results of Sackett $(1965 a, b, 1966)$ and others support such a notion. This investigation was designed to explore the possibility that rats given early exposure to complex musical forms would, in later choice situations, choose that which had been a part of their early experience. To insure sufficiently diverse alternatives in the test situation, the music of Mozart was employed for one exposure group, and the atonal music of Schoenberg was utilized for the second group.

\section{Method}

The Ss consisted of 65 Sprague-Dawley albino rats. bers. The Ss of one of the litters in the original exposure groups died, presumably as a result of poor maternal care, and, as a consequence, $20 \mathrm{Ss}$ born at the same time and raised under the same conditions but without exposure were added to the original groups. These Ss are referred to as delay Ss since exposure was begun on their twenty-first day of life.

The original groups consisted of 20 Ss exposed to Mozart music and eight Ss exposed to Schoenberg music. The delay groups consisted. of nine Ss in the Mozart and $11 \mathrm{Ss}$ in the Schoenberg groups. Seventeen Ss of the same age and raised in the same manner except without music served as the control group.

The chambers in which the Ss were raised consisted of an area $22 \times 18 \times 15$ in. equipped with a blower motor to circulate air. Inside this sound insulated area was a living cage with two separate sections $20 \times 8 \times 8$ in. At the top of the chamber and 6 in. above the living cage there was a 4 -in. speaker and an 8-w red light. Four tape recorders which were automatically controlled were used to present music to the Ss.

The test chamber was an unpainted plywood box $18 \times 12 \times 10 \mathrm{in}$. The floor was divided into two equal parts, each $9 \times 6 \times 10$ in., with a partial partition running about half of the width of the box. Both sections of the floor were individually hinged and spring loaded. The floor sections responded to S's weight by closing a microswitch located on the outside surface of the box. Separate electric timers recorded the amount of time that each microswitch was depressed.

Four timed pregnant albino rats were placed in the living quarters. At birth the pups were divided randomly into two groups, the Mozart group and the Schoenberg group. A schedule was used to insure that the groups spent an equal amount of time in each of the chambers. Any differences due to the particular exposure apparatuses were thus randomized between the groups. The Mozart group was exposed to vocal and nonvocal selections of Mozart music $12 \mathrm{hr}$. each day for 52 days. The tapes, which were $3 \mathrm{hr}$. in length, were repeated four times during the day and consisted of music from Tlie Magic Flute, Symphonies No. 40 and 41 , additional opera music, and The Violin Concerto No. 5. The Schoenberg group was exposed to comparable periods of vocal and nonvocal music with selections including Pierrot Lunaire, Chamber Symphonies No. 1 and 2, A Survivor from Warsaw, Verklarte Nachte, and Kol Nidre. A microphone and 
Table 1. Mean Time Spent in Mozart and Schoenberg Compartments during Test for Various Groups

\begin{tabular}{lrrrr}
$\begin{array}{l}\text { Eperimental } \\
\text { Condition }\end{array}$ & \multicolumn{4}{c}{ Mean Time (Sec.) in Compartments } \\
Mozart Originals & 19 & 1024.18 & 753.40 & $7.27 * *$ \\
Mozart Delays & 8 & 986.47 & 796.09 & $2.82 *$ \\
All Mozarts & 28 & 1012.47 & 766.64 & $7.40 * *$ \\
Schoenberg Originals & 7 & 859.71 & 902.96 & .29 \\
Schoenberg Deloys & 10 & 789.50 & 974.89 & 1.38 \\
All Schoenbergs & 18 & 819.06 & 944.61 & 1.27 \\
Control Subjects & 16 & 926.43 & 851.41 & 1.03 \\
\hline$* p<.03$ & & & & \\
$* * p<.001$ & & & &
\end{tabular}

voltmeter were used in an attempt to equalize the intensity of music in the two chambers. Delay Ss were placed in both groups on the twenty-first day of the exposure. These delay Ss were exposed to their particular music each day for the remainder of the 52-day period.

After 52 days all Ss were removed from the exposure apparatus and were placed in standard wire mesh cages for 15 days prior to testing. Each $\mathrm{S}$ was then given four test sessions, each of $30-\mathrm{min}$. duration, over approximately a 60-day period. All testing was done in the early evening hours. The $S$ could control his exposure to music by means of his position in the test chamber. While on one side of the box, $S$ received Mozart music; on the other side he received Schoenberg music. The music utilized in the test period was distinct from that which had been used during the exposure period. The side on which the particular music conditions were presented was determined randomly for a given test session with the only restriction being that each music condition appeared equally often on each side of the test chamber.

Time spent on a test-chamber side corresponding to a particular type of music was recorded in tenths of seconds by means of electric timers. When $S$ simultaneously depressed both floor sections, neither timer was activated, and a condition of no music resulted. All testing was done with the test chamber located in one of the sound insulated chambers used during the exposure.

\section{Results and Discussion}

Mean times in seconds spent in the respective music compartments over the entire test period were analyzed by means of two-tailed, dependent-t tests. Table 1 summarizes the results.

The Ss of both the Mozart original and the Mozart delay groups demonstrated a significant preference for the Mozart music. In fact, 28 Ss out of a total of 29 originally exposed to Mozart music spent the larger portion of their test time in the Mozart chamber. The Ss of both Schoenberg groups did not significantly exhibit a preference nor was any preference apparent among the control animals.

The fact that both the original and delo sozart
Ss spent significantly more time in the Mozart chamber during the test period argues for some preference or attachment behavior stemming out of the prolonged exposure with Mozart music. It is of interest that this effect was observed even though the test extended over a 60-day period. The absence of a consistent preference among control Ss limits a possible objection that Mozart music is innately more rewarding (or less aversive) than the atonal Schoenberg music.

If the behavior of the Mozart Ss of this study reflects some underlying attachment process, the concept of attachment (Cairns, 1966) must of necessity be broadened to include more than social or nonsocial objects. Studies of attachment behavior have typically employed some concrete stimulus, but in this experiment the "object" of attachment was itself abstract.

The preference behavior of the Mozart Ss could be attributed to "imprinting" or some other form of "exposure learning." Cairns (1966), in a review of studies of attachment in mammals, has advanced the notion that both social and nonsocial attachment behavior results from an associative conditioning process. In this theory, the major variable in attachment is length of association with a given object.

The behavior of the Schoenberg Ss poses a problem. In the theory advanced by Cairns (1966) it would be necessary to attribute the fallure of the Schoenberg Ss to show attachment to a deficiency in some stimulus characteristic such as "intensity," "vividness," or "attention-getting." It may be that attachment behavior requires some level of stimulus complexity appropriate to the developmental and/or experiential level of the organism. Perhaps Schoenberg music is too complex, i.e., lacks the necessary redundancy, to be an appropriate "object" of attachment for the lowly rat.

\section{References}

Burtt, H. E. An experimental study of early childhood memory. J. genet. Psychol., 1932, 40, 287-295.

Caims, R. B. Attachment behavior of mammals. Psychol. Rev.. $1966,73,409-426$.

Dember, W. N., \& Earl, R. W. Analysis of exploratory, manipulatory and curiosity behaviors. Psychol. Rev., 1957, 64, 91-96.

Gibson, E. J., \& Walk, R. D. The effect of prolonged exposure to visually presented patterns on learning to discriminate them. $J$. comp. phy'siol. Psychol., 1956, 49, 239-242.

Gibson, E. J., Walk, R. D., Pick, H. L., \& Tighe, T. J. The effect of prolonged exposure to visual patterns on learning to discriminate similar and different patterns. J. comp. physiol. Psychol., $1958,51,584-587$.

Sackett, G. P. Manipulatory behavior in monkeys reared under different levels of early stimulus variation. Percept. mot. Skills, 1965, 20, 985-988.

Sackett, G. P. Response of rhesus monkeys to social stimulation presented by means of colored slides. Pcrcept. mot. Skills. $1965,20,1027-1028$.

Sackett, G. P. Development of preference for differentially complex patterns by infant monkeys, Psychon. Sci., 1966, 6, 441442.

Sluckin, W. Imprinting and carly lcarning. Chicago: Aldine Publishing Co., 1965. 